\title{
Immediate implanto-prosthetic rehabilitation after socket shield technique of implant placement -4 years follow up - a clinical study
}

Smojver I., Illeš D., Sušić M., Gabrić D.

Universitiy of Zagreb, School of Dental Medicine

Department of Oral Surgery

\section{Background}

Socket shield technique was introduced by Hurzeler and associates in year 2010., which is used at immediate implantation in order to preserve buccal wall bone. During, tooth extraction, buccal root with periodontal ligament should be left in alveola and implant is inserted little bit towards palatal wall bone, in direct contact with buccal part of the root.

As written above preservation of buccal bone and soft tissues has a huge influence on esthethic outcome of implatprostethic work.

\section{Aim/Hypothesis}

The aim of this clinical study was to investigate clinical success of the socket shield technique and to evaluate its outcome 4 years after surgical and prosthetic rehabilitation.

\section{Materials and Methods}

This clinical study constituted of 21 patients with strong indication for tooth extraction in the frontal part of the maxilla. Patients were divided due to their clinical indications:

1. Postendodontic horizontal tooth fracture where the fracture line is prosper enough to preserve buccal tooth root and immediate implant placement 2. Postendodontic submarginal fracture when patient rejects ortodonthic tooth extrusion.

3. Crown fracture of vital tooth beyond the marginal bone surface, but patient is not willing to access ortodontic therapy or conservative treatment.

In each group consisted of 7 patients. Partial resection of palatal root was performed in each patient with a view to preserve buccal root as well as buccal bone wall. After resection alveolar bed for implant, located more palatal regarding on buccal root left in alveola, was prepared. Before implant was inserted a buccal root was smeared with Emdogain gel (Straumann, Basel, Switzerland). After all, immediate crown was made following non-functional loading concept.

Patients were threaded with antibiotic therapy during 7 days after surgery. After 4 months a permanent implantoprostethic substitute was made, while $x$ ray analysis was made after 6 months and after 4 years all patients were controlled by $\mathrm{x}$ - ray analysis and esthethic evaluation has been made.

\section{Results}

Patients did not have any kind of complications after surgery. Immediate crowns were replaced with permanent tooth crowns after 4 months. Soft tissue contours were preserved in all cases, also buccal bone wall was preserved after 6 months and after 4 years. In a period of following 4 years there were no biological complications. There were only mechanical complications with 4 patients regarding screw loosening. All complications occured after 1 year in function and were resolved in one visit.

\section{Conclusions and Clinical implications}

With buccal bone wall preservation as well as a preservation of gingival tissue using technique of immediate implant placement, very good esthetic results were achieved. By deciding which patients are candidates for this surgery indications and guidelines written above need to be followed.

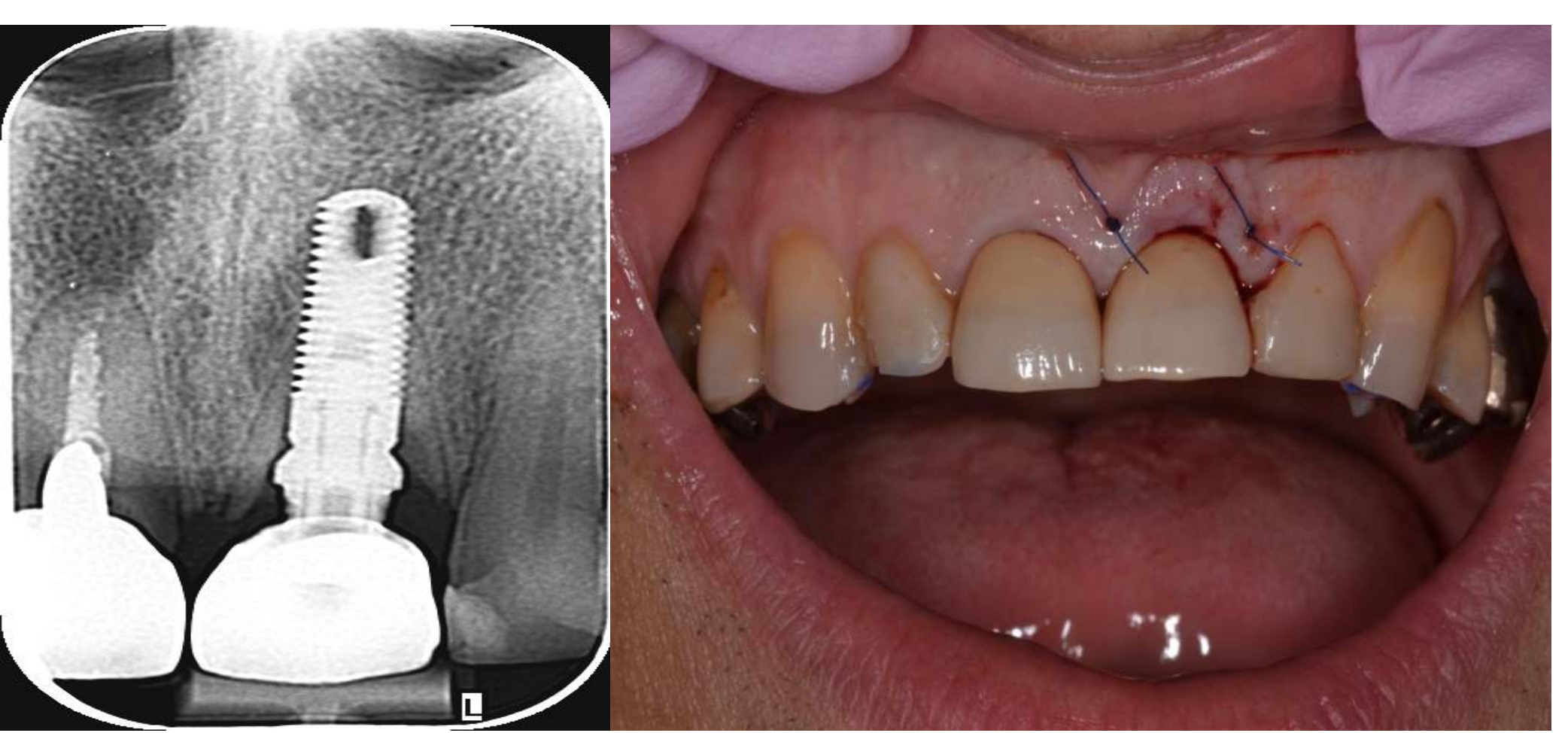

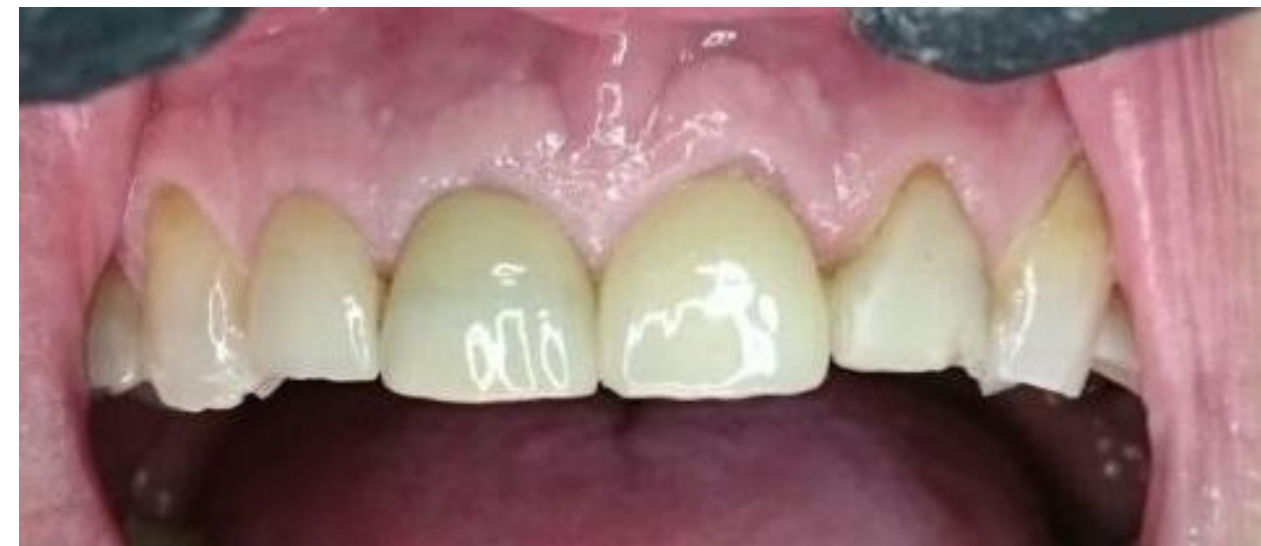

Final crowns after healing period of 6 months

Immediate crown and post op $x$ - ray

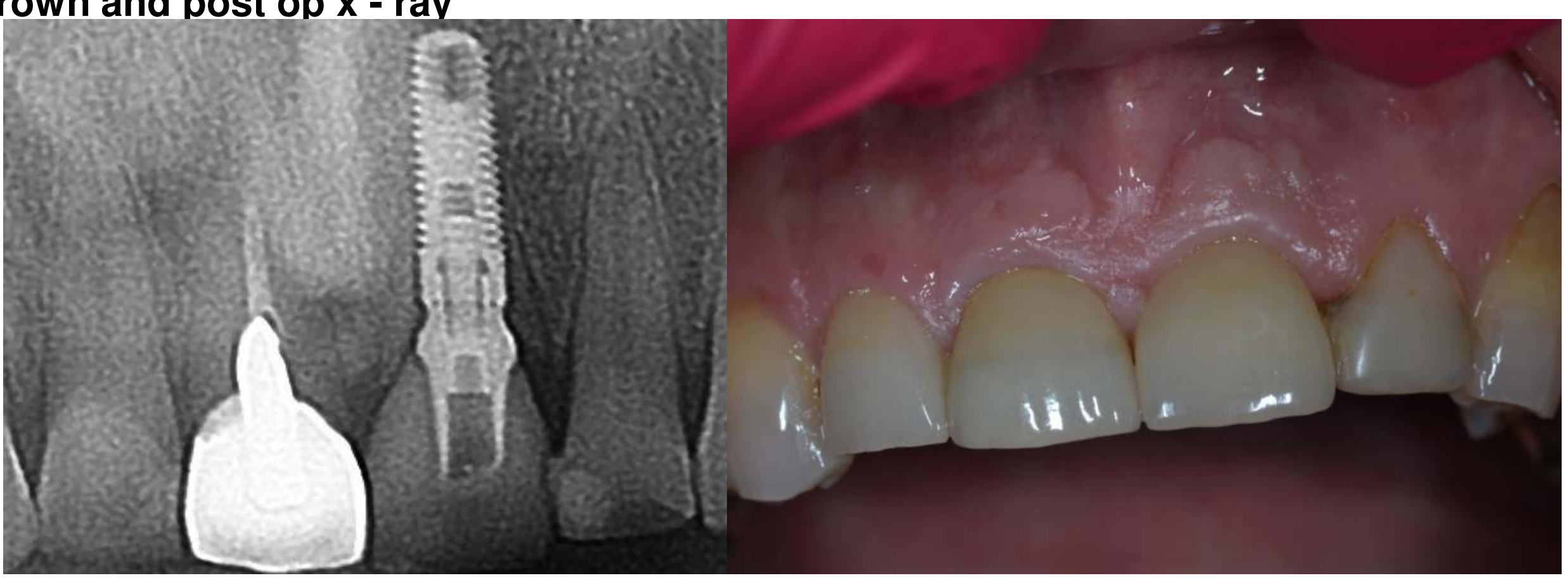

After 4 yrs - follow up - x -ray and clinical appearance 